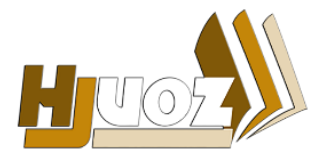

hjuoz.uoz.edu.krd p-ISSN: 2410-7557 e-ISSN: 2518-5128
كُوّارا زانستيّن مروّقايهتى يا زانكوّيا زاخوّ مجلة العلوم الانسانية لجامعة زاخو

Humanities Journal of University of Zakho (HJUOZ)

Vol. 5, No. 3, pp. 616-627, Sept.-2017

\title{
تغريب الصورة الشعرية لدى سليم بركات
}

هشام محمد عبد الله 1* و محمد صادق جمعة إبراهيم2

1 قسم اللغة العربية، كلية التربية، جامعة الموصل.

2015م اللغة العربية، فاكولتي العلوم الإنسانية، جامعة زاخو، أقليم كوردستان - العراق.

https://doi.org/10.26436/2017.5.3.439

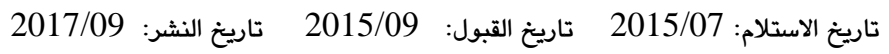

الملخص:

إن التغريب” De familiarization" يعني: كسر الألفة، على مستوى التركيب والمعنى. لكن إدراك دلالة التغريب في العمل الفني، يستغرق

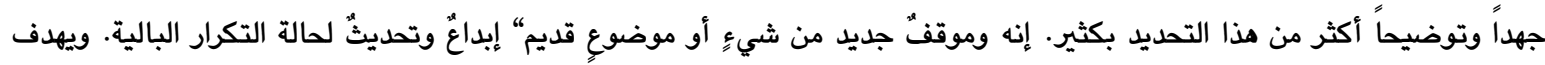

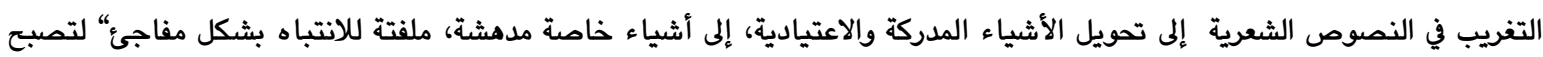

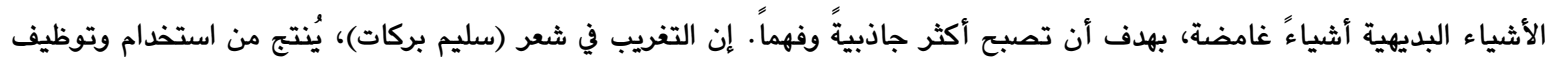

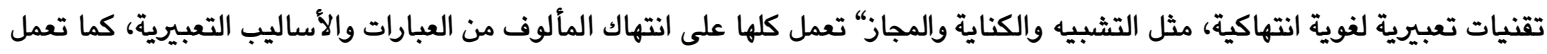

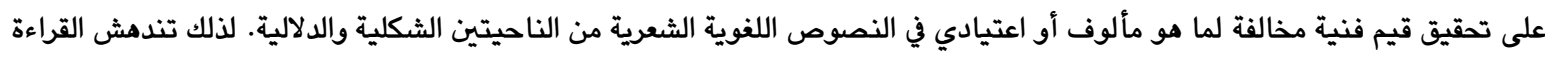
أمام لغة نصه الشعري، حين تبتدع الكلمات أنساقها الخاصة، وتبتكر الألفاظ دلالاتها، من تغريب السياقات والأنساق والعلامات والإثارات

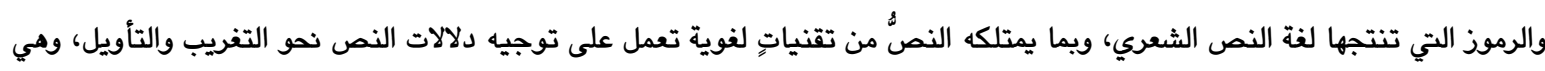
تقنية منتجةٌ بقصرٍ خاص للتأثير في قدرات التلقي التأويلية، وتعمل على كسر افق تلقيه باستمرار، حتى أن اللغة تبدو مهددة في تاريخ

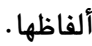

الأدبية اللغوية والأسلوبية التي تجعل من النص المُغرَّب نصاً مغايراً

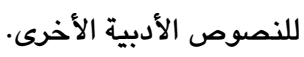
ومن أبرذ هذه التقنيات الفنية التي يستند عليها النص الشعري هي تقنية "الصورة الشعرية" .

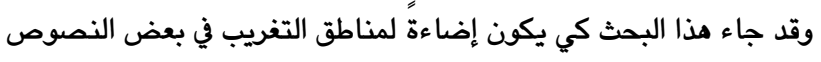

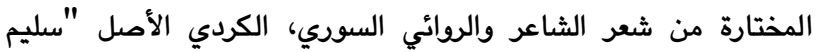
بركات". وقد قسمت البحث على فقرات ثلاث: الفقرة الأولى تهتم ببيان "التغريب في بنية الصورة الشعرية"، لأن الصور تلاثن

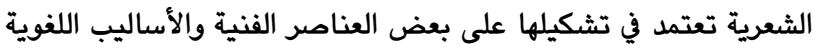

$$
\text { التي يوظفها الشعراء كاطارٍ فني. }
$$

والتغريب هو واحٍِِ من هذه الوسائل الفنية المهمة لدى سليم بركات.

\section{الكلمات الدالة: التغريب، الصورة، الشعر، سليم بركات.}

\section{1}

تنهض النصوص الأدبية الشعرية والنثرية، على بعض الخصائص الفنية

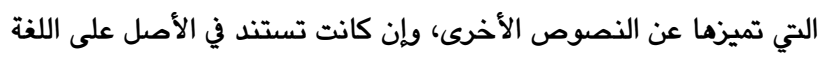

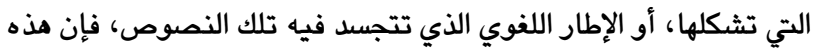
الخصائص الفنية لا يمكن الكشف عنها وتحديدها إلا بعد إدراكها والتفاعل

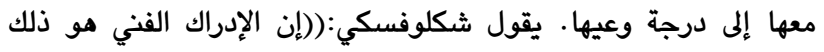

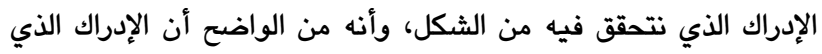

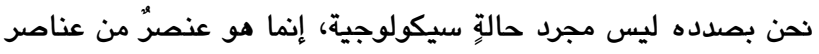

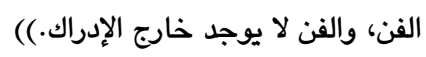
والتغريب يعدُّ تقنيةً من التقنيات الفنية الشكلية- اللغوية في النص الأدبي ) والثرات بشكل عام، والنص الشعري بشكل خاص، ويتأسس على بعض التقنيات 
طريق التفاعل فيما بينها، وذلك ما يجعلنا نشعر بأنها إبداع جديد بخلاف

$$
\text { ما هو حادث ومألوف. }
$$

وتمثل النصوص الشعرية فضاءا لغوياً خاصا تتشكل فيه الصور الشعرية بامتياز. ترتبط عادة الصور الشعرية بموضوعها، وتختلف هذه الصور باختلاف القدرة التعبيرية والرؤية الشعرية الخاصة لمبدع النص.

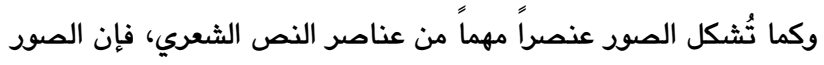

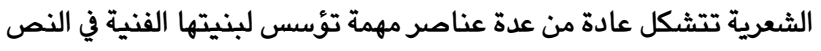

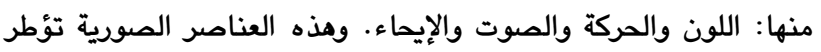

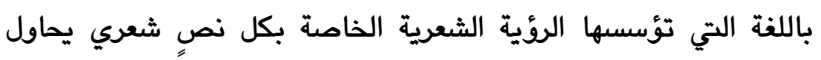
صياغة موضوعه. ولغة النص الشعري لدى سليم بركات، تلقي الضوء على ذاتها أكثر من موضوعها. تقوم هذه النصوص اللغوية على نمطٍٍ معين من النسج اللغوي المغرَّب

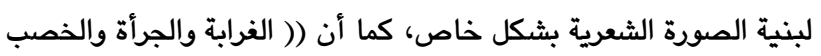

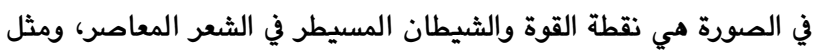

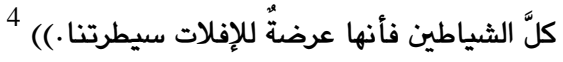

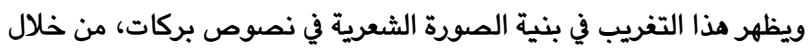
التصوّر والموقف الشخصي المغاير لجزئيات المعاني التي تشكل بدورها

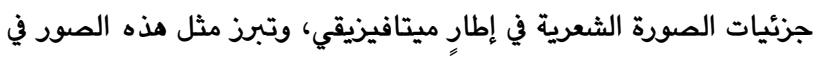
نص بركات الشعري بشكل متكرد في وصف عالم الحيوان والحشرات،

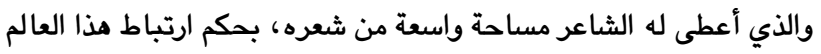
بيئته وأفقه الفكري، والذي يحاول دائماً إقامة علاقة جوهريةً بين أصول

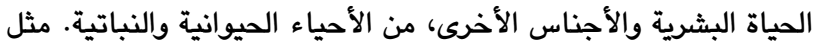

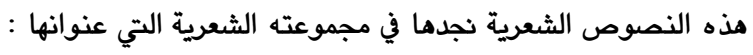

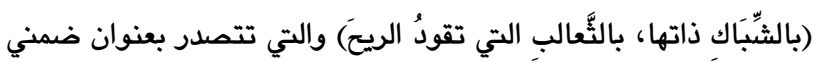

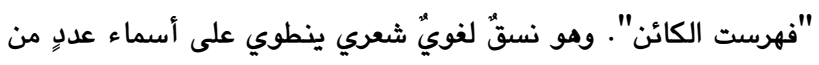

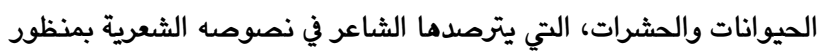
شعري مختلف، فيمنحها أبعاداً مغايرةً لكل ما هو معروف عنها في الإرث

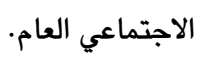

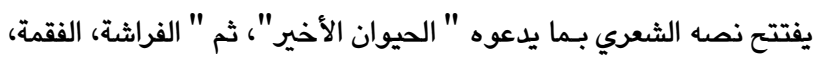

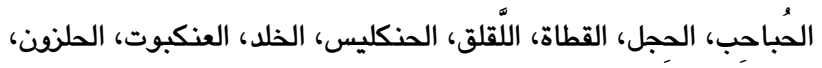

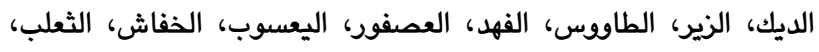

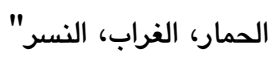

يخصص الشاعر هذه العناوين لتكون باباً يدخل منه إلى عالم نصه النسه الشعري الصاخب بالتغريب.
الفقرة الثانية تأتي بعنوان: "التغريب في علاقات الصور الشعرية". وتقوم على توضيح بعض أنماط التغريب التي يحدثها سليم بركات بين الصور الشعرية المتعددة في نصه الشعري. أما الفقرة الثالثة فإنها تبحث عن كيفيات التغريب في الصور الكلية

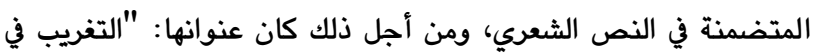
كيفيات إخراج الصور الشعرية". وكي تتمكن هذه الدراسة من ربط الفقرات الثلاث مع بعضها البعض،

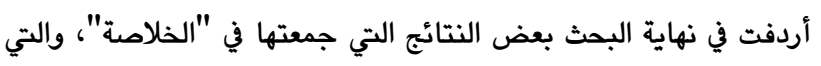
تكشف عن أهمية دراسة التغريب في النص الشعري، فضلاً عن اختصار النقار

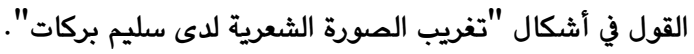

\section{2. التغريب في بنية الصورة الشعرية}

تمثل الصورة الشعرية أداةً مهمة من أدوات أدبية النص الشعري، فالصور

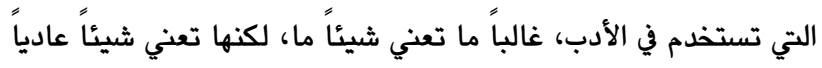
بطريقةٍ غير عادية" وهنا تكمن شعرية الصورة في النصوص الأدبية، بتقديم

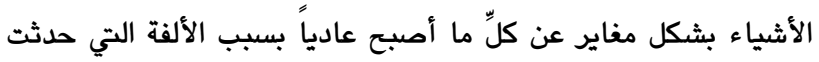

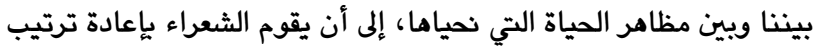
وتنظيم هذه الصور في سياقات مختلفة، غير معتادة أو مألوفة كالتي

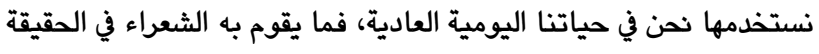
ليس ابتكار صورٍ جديدة غير موجودة من قبل، وإنما هو إعادة تنظيم

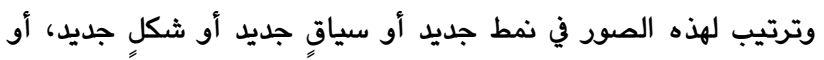

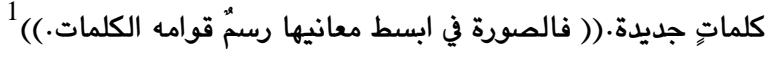

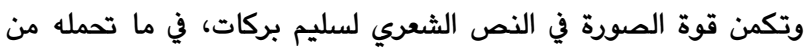

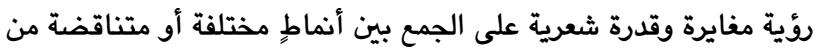

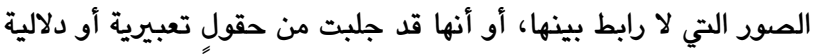

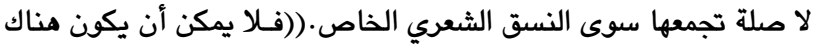

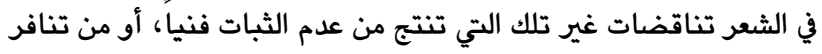

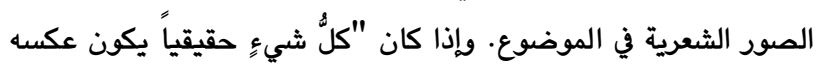

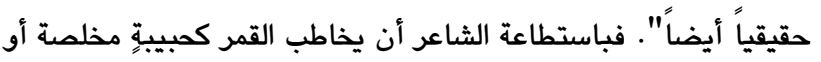

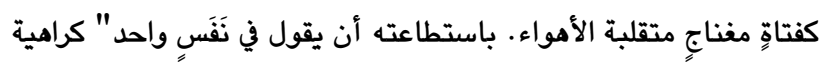

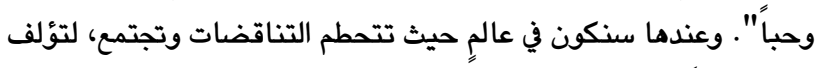

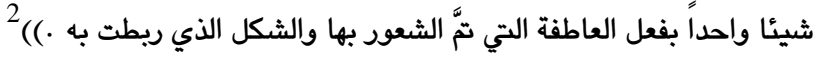

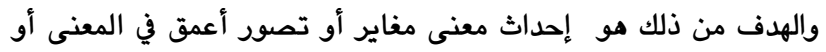
الشكل الذي تمنحه الصور المفردة في النص الشعري بشكل خاص. فالصور في الشعر((هي الشكل البصري المتعين بمقدار ما هي المتخيل

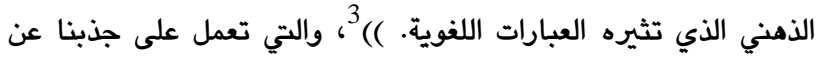


8 بل نسجُ طاهِ يتذوُّق الغيبَ كما يتذوقُّ الحساء.)

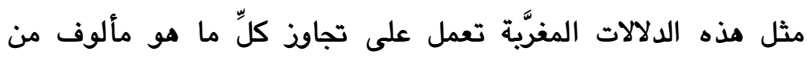
التصورات المتعلقة بالعنكبوت وينسيج العنكبوت، من كونه واهناً مُعرضاً للتمزق. أنه هنا يمثل نتاج الجماعة التي تنسج الحياة وليس نسيج الفرد الواهن.

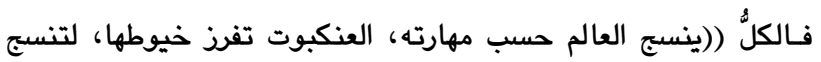

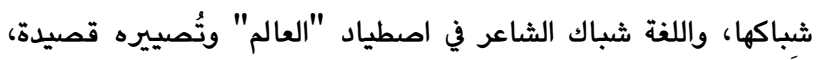

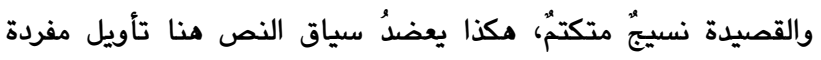

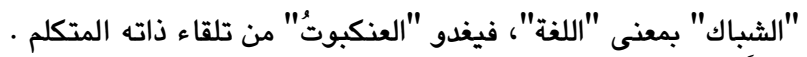

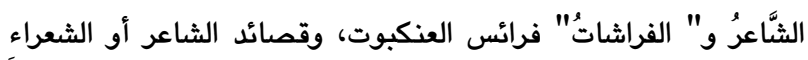

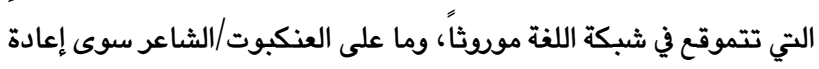

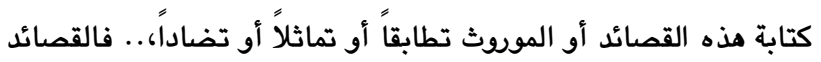
تغفو بهناءةٍ في شبكة اللغة (الموروث)، يأتي الشعراء (الطهاة)، ولكل توقيعه، إمضاؤه (ينثرون توابلهم)، لتكتسب القصيدة قوة دفي جديدة

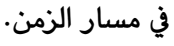
إنه نسج الشاعر يحيل المجرد (الغيب) إلى محسوس (الحساء)، حتى يكون

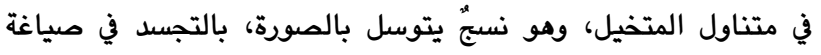
اللَّمرئي في مواجهة نسج الحكيم الذي يتوسل بالمفهوم والمقولة في تسمية

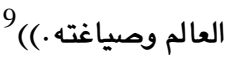

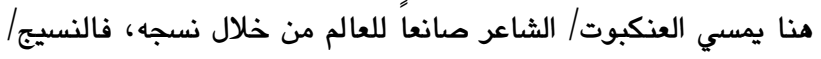
الشعر، يتحول في نص بركات إلى عتبةٍ نصية تقع بين عالم الظاهر الموهن

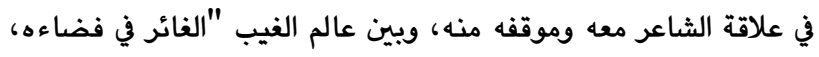

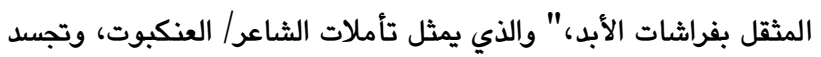

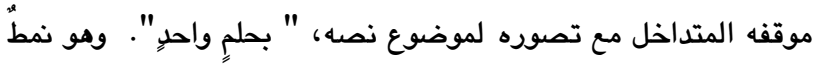
من التأملات الشاعرية التي(( تعطينا عالم العوالم. إنها تأملات كونية. إنها انفتاح على عالمٍ جميل، على عوالم جميلة، وهي تعطي للا(أنا) (لا أنا)

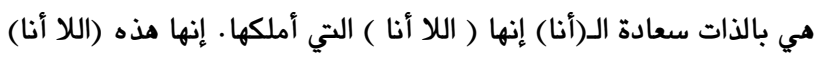
التي تسعد أنا الحالم)).

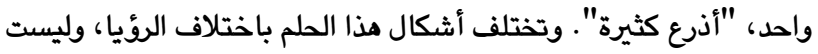

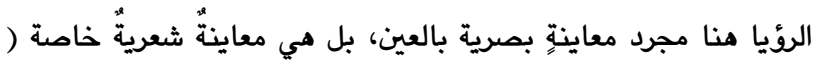
بعين الشاعر- شَباكه ) التي ترى ما وراء الآني الظاهر.

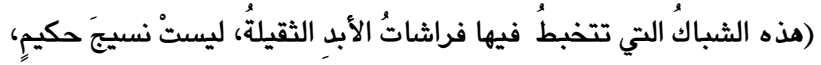
11 بل نسجُ طاهِ يتذوُّق الغيبَ كما يتذوقُق الحساء.

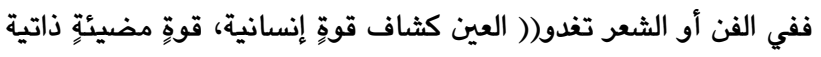
تأتي لترتقي بأضواء العالم، مناك تأملات النظرة الثاقبة، تأملاتٌ تتحرك
(إذ تومئُ عناوين المجموعة إلى قصدية متعمدة في عملية العنونة، تتساوق مع القصدية المتعمدة في الكتابة الشعرية ذاتها لدى سليم بركات، بوصفها كتابة تنسِّق النظام الدلالي للغة، بتطابق الدال مع المدلول رافعة التعبة راية

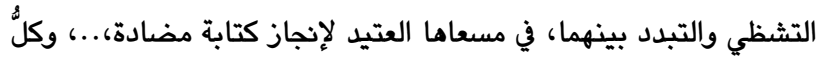

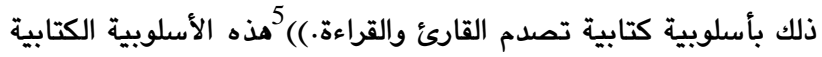
لدى بركات تقوم على مغايرة الصورة الشعرية الخاصة بتلك

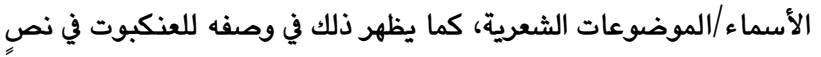

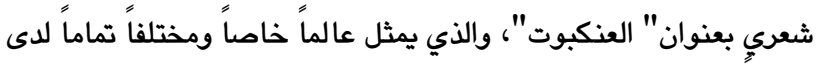

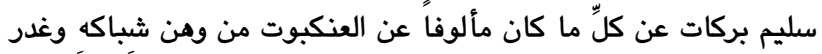

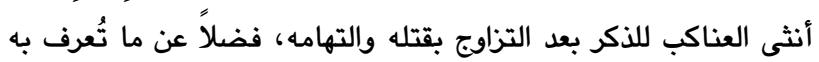
العناكب من إثارة للرعب لمن يتفاجأ برويتها. إن تغريب بركات لكل ذلك العُرف عن العنكبوت يأتي من خلال مغايرة

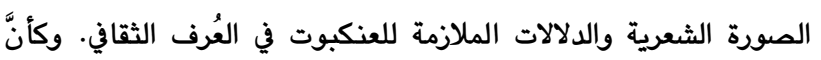
بركات يرى العالم من خلال أعين العنكبوت المتأمل في عمق الغيب: " العنكبوت يركات المبات

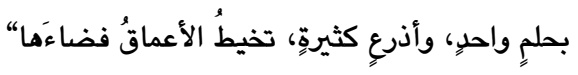
ويأذرعِ كثيرةٍ يشعل المساءُ قناديلَ أشباحه. لكن،

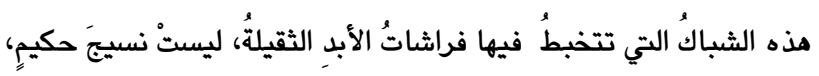
بل نسجُ طاهٍ يتذوقُق الغيبَ كما يتذوقُّ الحساء. ( الطهاةٌ لا ينسجون الشبّباكَ. الطهاةُ ينثرون توابلهم على الذي في الشِّباك) ما مَُّ، كلٌّ ينسجُ خطابَهُ بالأذرع الكثيرة الهادئة، والسطورُ تتقاطعُ بالرفيف الهادئ لأجنحة الموتْ. 6

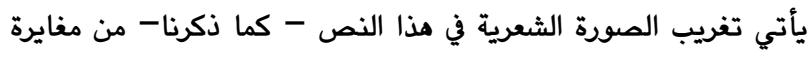

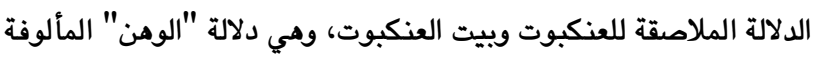

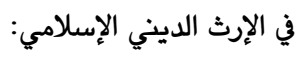
( (مثلُ اللذين أتخذوا من دون الله أولياء كمثل العنكبوت اتخذت بيتاً،

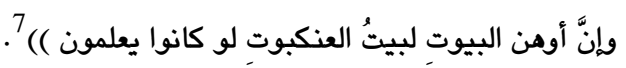
و الدلالة المغايرة التي تمنحها الألفاظ الخاصة لبنية النص الشعري هنا،

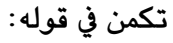

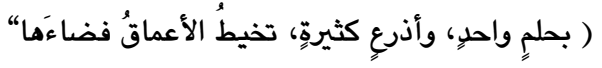

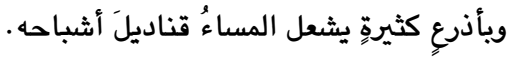
لكن، هذه الشباكُ التي تتخبطُ فيها فراشاتُ الأبدِ الثقيلة، ليستْ نسيجَ حكيمٍ، 
مدققاً فيما يخص المشاعر التي يوجهها إلى مذه الأشياء، ومنا يلجئ

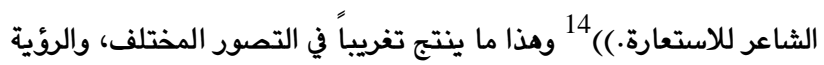

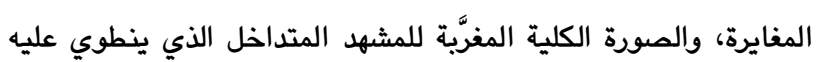
المنظور الشعري.

\section{3. التغريب في علاقات الصور الشعرية}

إنَّ التغريب في الفن والأدب عموماً ينطلق من نوعٍ من التمرد في كيفيات التعامل النصي مع الثوابت والأصول التي تنطوي عليها أقطاب المحاور والعلاقات الفاعلة بين الممارسة الفنية والموضوع، بين ما هو موجود في الأصل وما يمكن إيجاده، لأن (( الإبداع الحي - كما يرى الماركسيونلا يمكن أن يتقدم نحو الأمام دون التمرد على التراث الرسمي، والأفكار والمشاعر التقليدية والصور المبتذلة والتعبيرات البالية، فكل اتجاه جديد يسعى إلى التواصل المباشر الأكثر صدقاً بين الكلمات والمشاعر، فالفن الذي يفقد الإحساس بالكذب الاجتماعي لا بدّ وأن يهزم نفسه من جراء

$$
\text { التصنع، فيتحول إلى التكلف في الأسلوب)).15 بالإسل }
$$

وأسلوب سليم بركات في التعامل مع اللغة ومع الدلالة الشعرية التي تنطوي عليها صوره الشعرية، ينطلق من هذا التمرد والانقلاب على الثوابت الثقافية والأسلوبية، والخرجج على الأصول الفنية التي تؤصلها الممارسات الفنية الخاصة بشكلٍ من إثكال التعبير الأدبي.

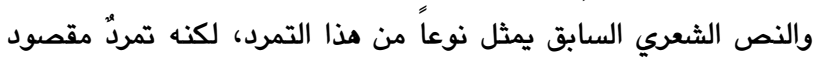
لأجل إحداثِ نوعِ من التغريب الدلالي في التصور الشعري. كما يمكن بيان هذا التمرد النسقي في شعر بركات، حين تندهش القراءة أمام لغة نصه الشعري، وحين تبتدع الكلمات أنساقها الخاصة، وتبتكر الألفاظ دلالاتها، من العلاقة القائمة بين حركة النسق الشعري، وبين انفتاح الذات الشاعرة على الآتي، أو ما سيأتي، من الأفعال والأنساق الزمانية والمكانية التي تنتجها لفة النص الشعري، ويما يمتلكه نص بركات من آليات لفوية تعمل

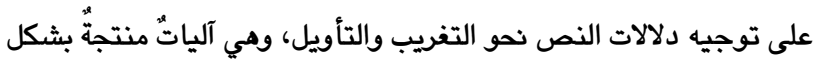
خاص للتأثير في قدرات التلقي التأويلية، وتعمل على كسر افق تلقيه باستمرار، ((حتى أن اللغة تبدو مهددة في تاريخ ألفاظها، وفي صميم شهوتها كاحتفالٍ بلاغي لتغدو إثاراتٍ محضة تدل على الشيء تدليلاً

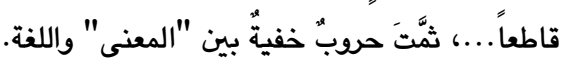

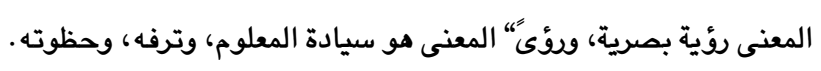
أما اللغة فهي البطش)) .16 ويظهر مثل مذا التمرد والبطش اللغوي بكثافة في مقطع شعري آخر من القصيدة السابقة، تستند اللغة فيه على تغريب التصور الشعري، الذي يؤكد تغريب ملكة التخيل أو تغريب الصور المتخيلة وتغريب علاقات التشبيه التي يقيمها سليم بركات بين المشبه

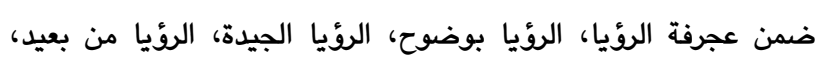

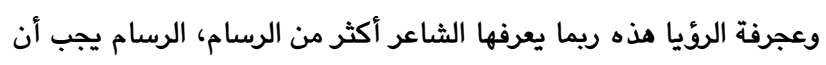

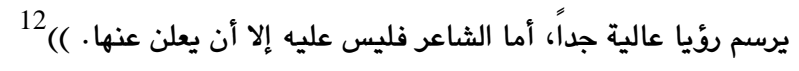
كما يرجع تغريب الصورة في نص سليم بركات إلى كيفيات توظيفها

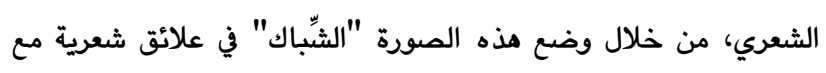
تصورات شعرية مختلفة، وضمن السياق اللغوي في النص الشعري ذاته،

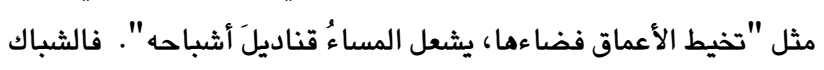

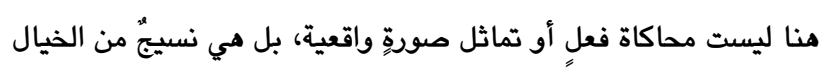

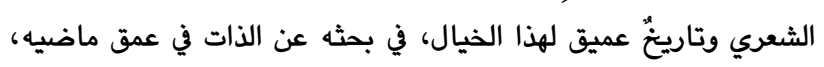

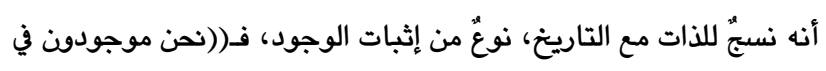
نوعٍ من المتاهة، لا نتمكن من إيجاد الخيط الذي يسمح لنا بالخرجج منها ويدون شك لا يجب أن نجده. لذلك نربط خيط التاريخ في المكان الذي يقطع فيه خيط ذكرياتنا (الشخصية) ونعيش في وجود ( حياة) أجدادنا

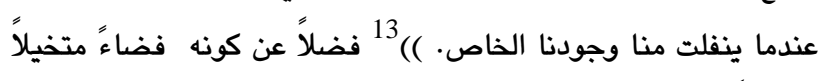

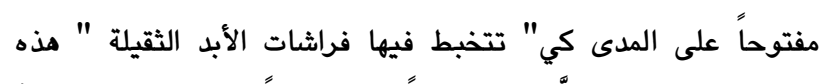

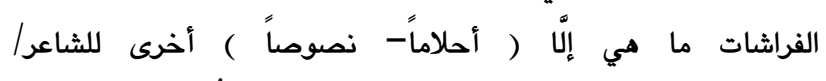

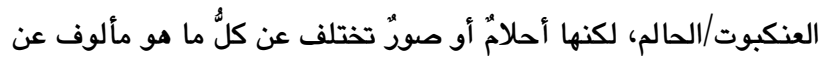
مثل هذا الموضوع، لأن رؤية الشاعر الحالم في عالم الغيب في لحظة ما، تصطدم مع رؤية العنكبوت اليقظ، الذي يرتقب بكل صبر مزة الشِّباك

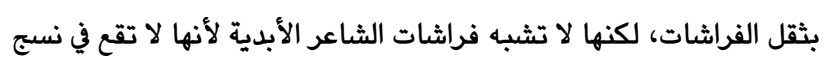
حكيم ، بل في" نسج طاهٍ يتذوق الغيبَ كما يتذوق الحساء" والطاهي هنا هو الشاعر نفسه. وهنا تكون المفارقة بين رؤية الشاعر الذي حاول أن يرى العالم من عيون العنكبوت، وأن يقف فوق شبباكه، ويِن الرؤية الواقعية التي يمنحها الشاعر للعنكبوت والتي تظهر في النص من خلال تغريب التصور المألوف عن العنكبوت في أنه يصيد بشِباكٍ واهنٍ، فالتغريب يكمن هنا في بنية

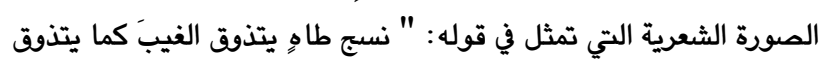
الحساء". فالصورة مبنية من نسيجٍ من الذيال الذي استطاع أن يقيم

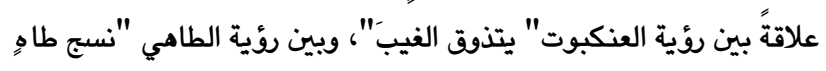
يتذوق الحساء". وهذا هو التغريب الذي يتمحور حوله النص. ومن (المؤكّد أن الشاعر ينبغي أن يحاول لؤية الأشياء كما هي في الواقع، ولكن لا شيء حقيقي إذا ما أفرد في عزلةٍ، محضاً في حالة اكتفاءٍ ذاتي. فالواقع يتضمن " العلاقة "، وما أن تدخل "العلاقة" حتى تجيء "العاطفة" بالنسبة للبشر. ومكذا فإن الشاعر لا يستطيع أن يرى الأشياء

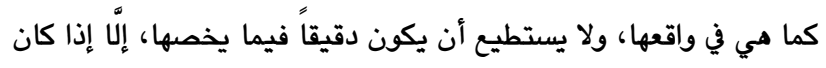


يكسرُ البُندقَ بأسنانه". فالاستعارة التي تجمع هنا بين العدم الذي يدلُّ

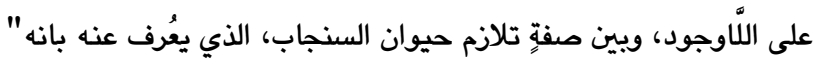

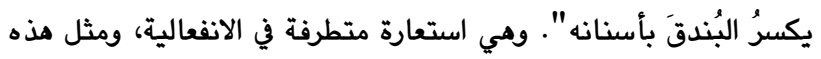
الاستعارات ((يعوزها المحتوى الدلالي وتعمل بوصفها أدواتٍٍ انفعاليةً

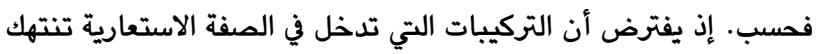
الافتراضات اللغوية القائمة، كما هو الحال في العلاقات الخاصة المناسبة

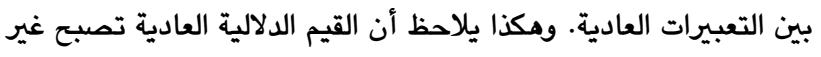

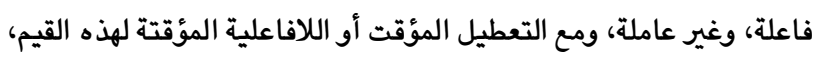

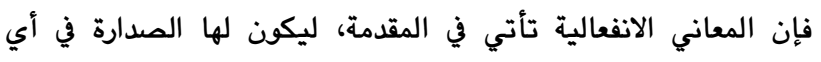
استعارة.(19) إن المعاني

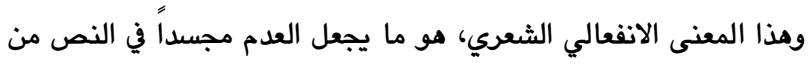

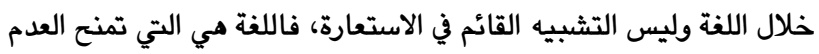

هوية انفعالية استعارية شعرية :

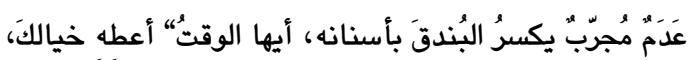

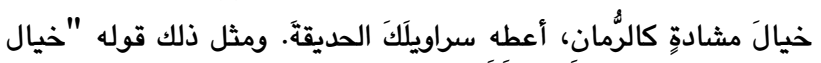
الوقت، خيالٌ كالرمانة، سراويلك الحديقة " فهي ايضاً استعارات انفعالية

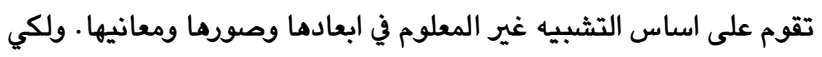

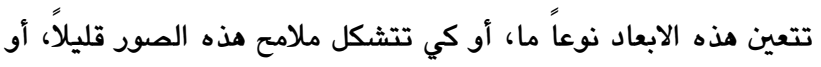

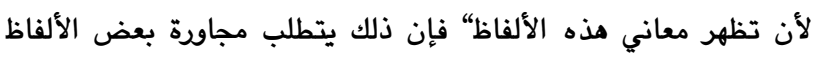

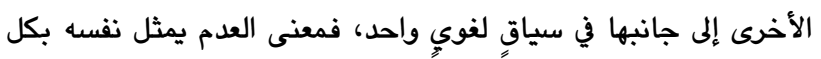

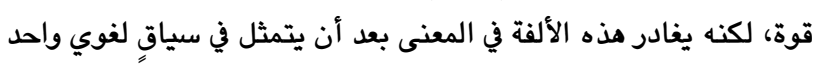

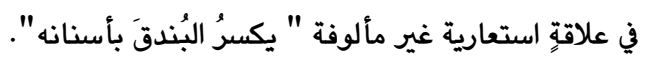

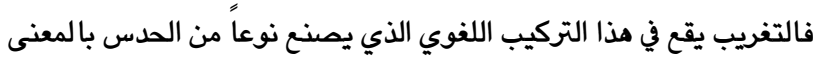

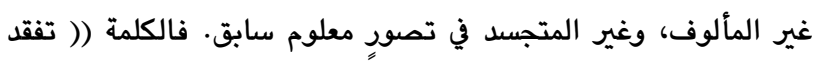

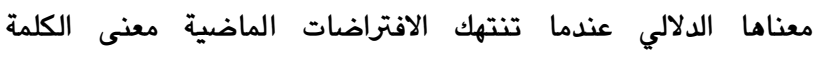

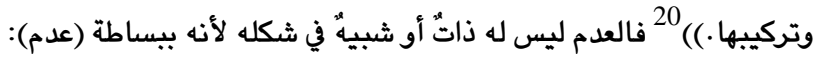

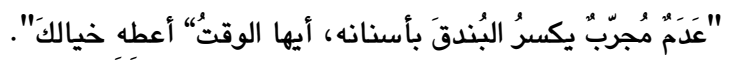

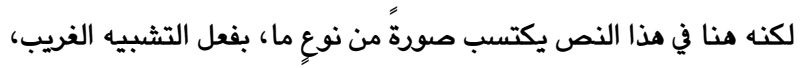

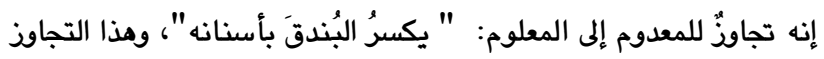
يمثل تغريباً استعارياً بامتياز .

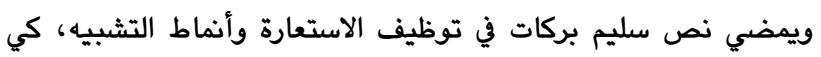
يسخر إمكانيات الصورة الشعرية في إثارة التغريب والاندهاش، ومن ذلك تلكات

قوله: - عُضَّ الضرورات، يا وقتُ. تعمل الاستعارة هنا على تغريب الصورة

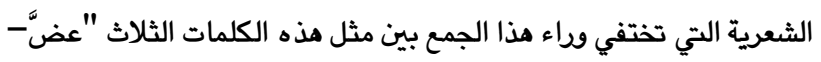

والمشبه به، قصد التغريب في الصورة الشعرية، ويظهر ذلك في المقطع التالي :

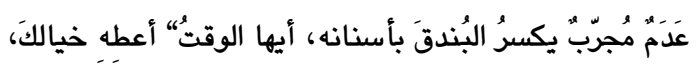

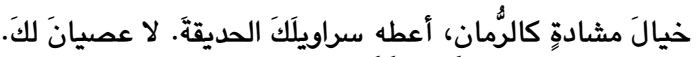

عُضَّ الضرورات، يا وقتُ: تخلو إلاًّ من غدِ مسترشداً بالأكيد التائه

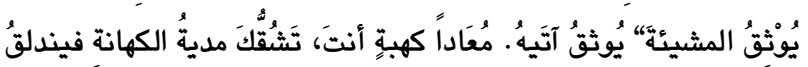

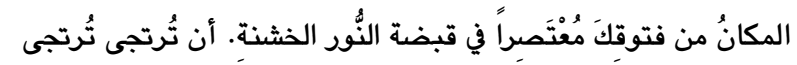

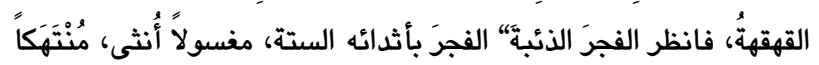
بالمُخصِب الأزليَّ، يجالسُكَ أيها المتوعِّكُ من العافية.

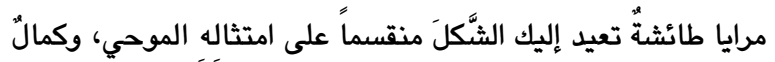
يلتهمُكَ في وليمته الفاحشَّة يا وقتُ. متكئًاً على خرائبه المَرحِِة يرصدُ الوقتُ نعامةً الفراغ. عُضَّي، أيتها العافية، على أناملِ الوقتِ طويلاً كي تُعيدي المكانَ إلى حَنينه... عُضِّي. 17 يُعدُّ الشَعر من الآليات القليلة التي تتمكن من خرق قوانين الزمن، فبالشعر

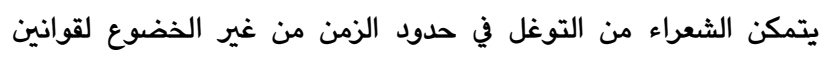

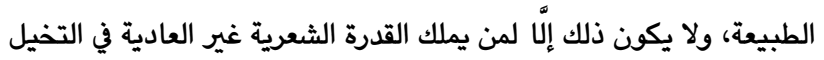

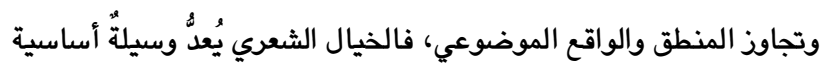

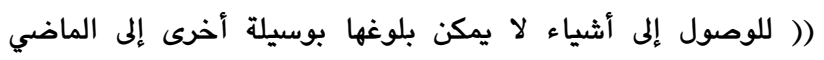

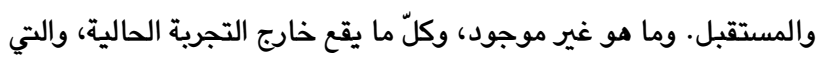

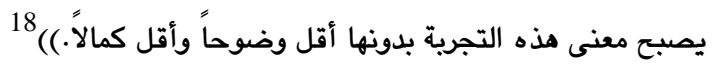

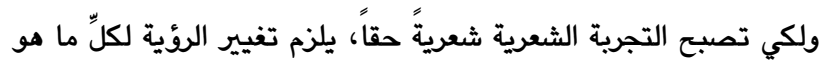

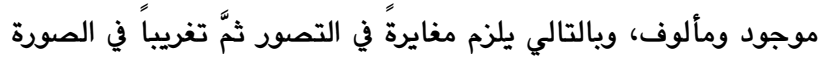
الشعرية، وتغريباً في قيمة هذه الصور ودلالاتها ومضامينها.

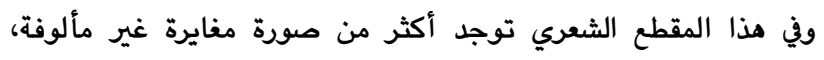

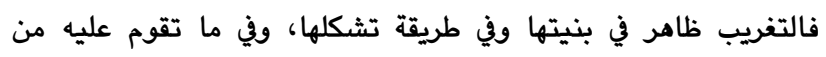
أغراض، أو ما تنطوي عليه من معاني ودلالات. مثل قوله :

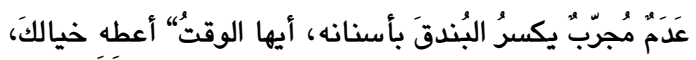

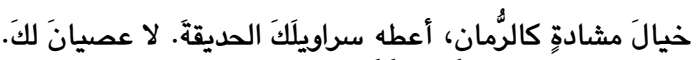

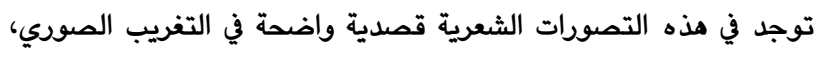

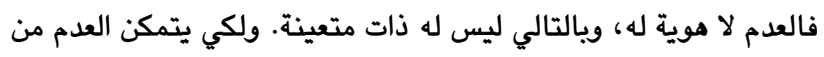

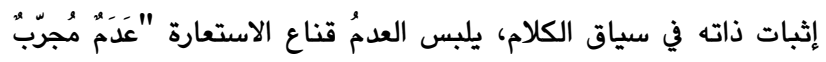


باقتحام باب الخيال، فالشعر عالثٌ يحاول الشاعر أن يبنيه مثل ما يراه، و يحاول ان يعيش فيه في الوقت ذاته" فعالم ((الخيال هو عالم الإيمان

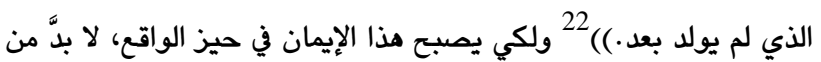
أن يتحقق هذا الوجود في النص الشعري من خلال جماليات الصورة

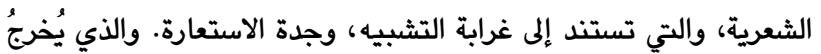
كلَّ ذلك إلى التحقق في بنية النص اللغوي هو تغريب الرؤية أو المنظور.

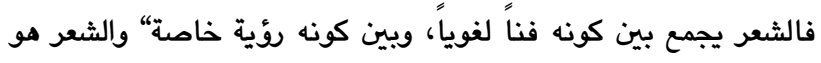

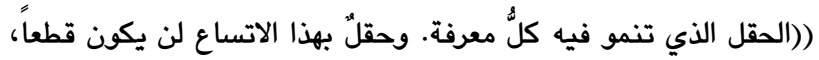

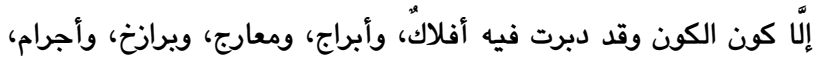

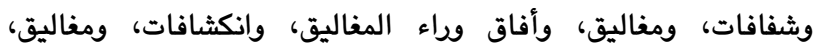

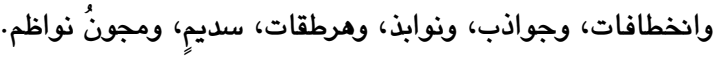
الشعر هو لغة الذهول الأول، الذي أعترى الحضورات مبصرة نفسها في بذخ الظاهر" هو رنين الحدوث الغامض للنشآت، هو التدوين الهاذي لانبلاج

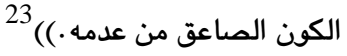
ومن أجل هذا، تبدو نصوص سليم بركات الشعرية كأنها تخرج من منظورٍ فانتازي غريب، فتخرج بالتالي استعاراته وتشبيهاته مغرَّة غير مألوفة، تبرة

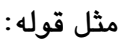
- تَثَقُقَْ مديةُ الكهانة فيندلقُ المكانُ من فتوقِكَ مُعْتَصِراً في قبضة النُّور الخشنة. هنا يتجسد الزمن من خلال الاستعارة التي تستند على تشبيه

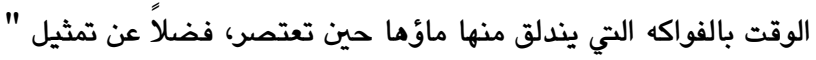

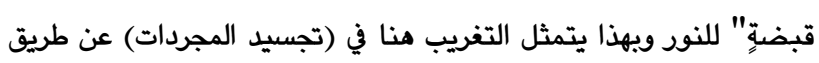
الاستعارة، ويظهر ذلك أيضاً في قوله:

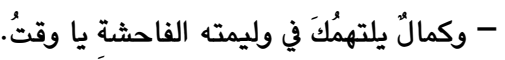

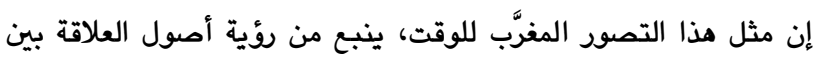

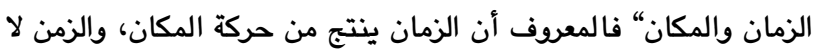

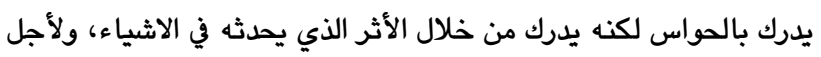

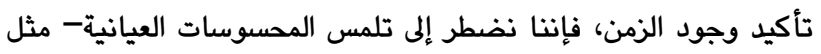

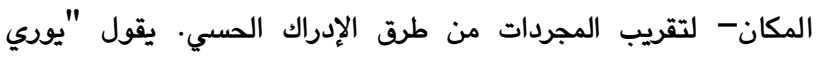
لوتمان" : ((فالإنسان دائماً يحاول أن يقرب لنفسه المجردات من خلال تجسيدما في ملموسات، وأقرب هذه الملموسات هي الإحداثيات المكانية، فالتفكير يخضع لعملية ترجمةِ: المجردات تترجم إلى محسوسات: فاللًا

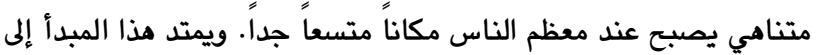

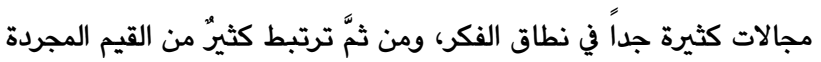

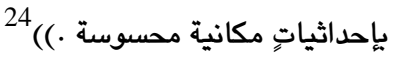
وهذا التجسيد للمجرد هو سمة هذا المقطع الشعري، والذي يظهر في عدة آليه
الضرورات- الوقت"، والتي تنتمي كلُ واحدةٍ منها إلى حقلٍ لغوي مختلف في الاستعمال اليومي، فالقدرة على تشكيل صورة شعرية مدهشة من عملية

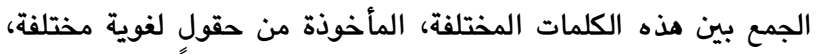
ضمن سياقٍ شعري واحد، هو ما أضاف التغريب على هذا المقطع

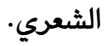
( بالأكيد التائه يوِْْقُ المشيئَة). إن وصف (الأكيد بالتائه) يندرج ضمن

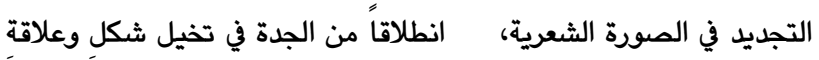
الاستعارة لمثل مذا التركيب اللغوي.

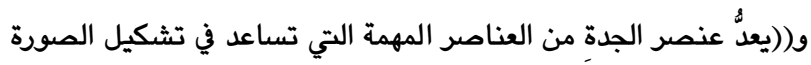

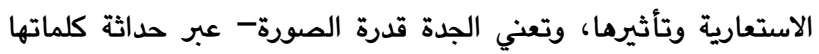
ومادتها- على الكشف عن أشياء لم ندركها من قبل.

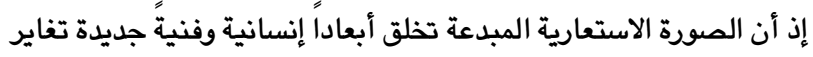

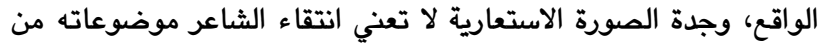

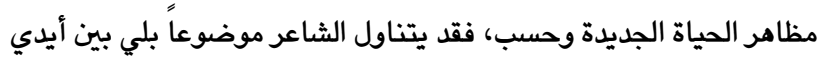

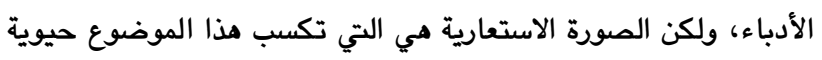

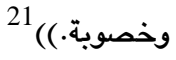

وتظهر هذه الصور الاستعارية المبدعة غير المألوفة في المقاطع التالية، وخهما،

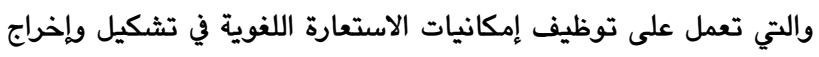

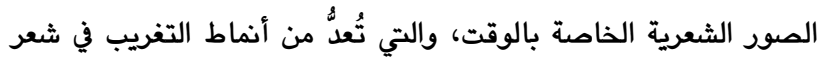

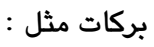
- مَتَُقُّكَ مديةُ الكهانة فيندلقُ المكانُ من فتوقِكَ مُعْتَصِراً في قبضة النُّور

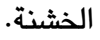
- - مانظر الفجرَ الذئبةَّ، الفجرَ بأثدائه الستة.

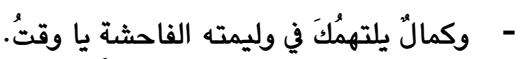

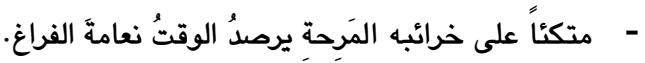

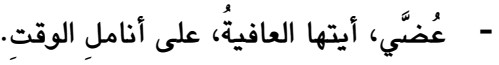

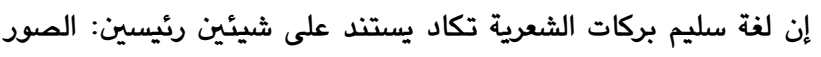

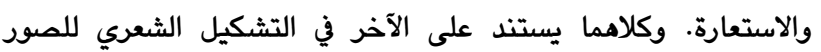
والمجازات والنسق اللغوي للنص، مثل قوله:

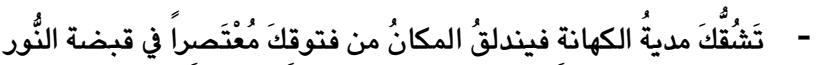

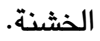
إن التمكن من إيراد مثل هذه التشبيهات والصور المغرَّبة يكون من خلال تفعيل قدرات الخيال الابداعي، كي يتمكن من تشكيل صوره الخاصة التي قد تكون جديدة كلياً.

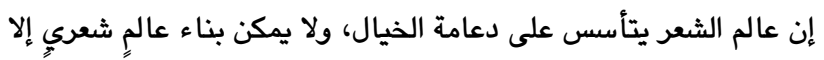


أخرج مثل هذه التصورات غير المألوفة، مثل ما نجد في الأبيات التالية :

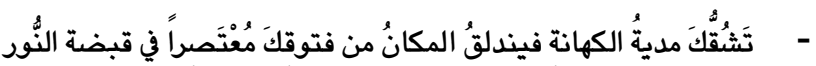

الخشنة.

- - مانظر الفجرَ الذئبَّة" الفجرَ بأثدائه الستة.

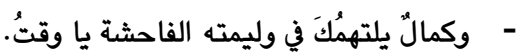

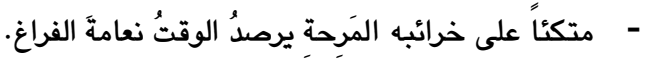

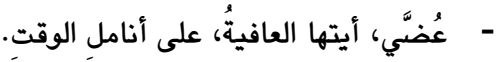

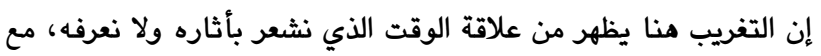
التصور غير المألوف الذي يتضمنه نسق التشبيه. فالوقت كيانٌ

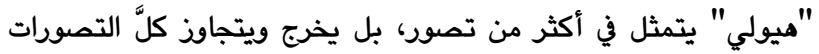
المتعلقة به بشكل مستمر. فالوقت هنا قربان الآلهة، الذي يتمخض

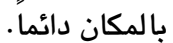
والوقت " الفجر" هنا ذئبةٌ والدة، والوقت فريسةُ الكمال، والوقت مترصِّمّ للفراغ، صيادُ مترصدُ لنفسه" للفراغ". إن مثل هذه التصورات الغريبة للوقت هي التي تضفي تغريباً على هذا

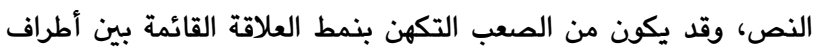
التشبيه التي جمعها الشاعر في سياقٍ نصي واحد.

\section{4. التغريب في كيفيات إخراج الصور الشعرية}

تتجلى الصور المغرَّة في النصوص الشعرية لدى سليم بركات من خلال:

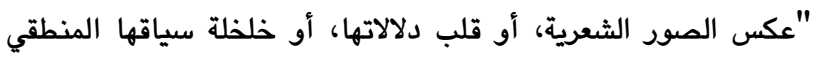

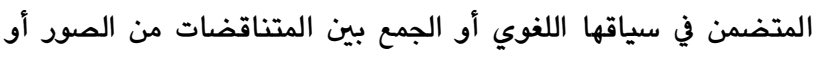

المعاني وفي تحوير الوظيفة الدلالية للصور الشعرية".

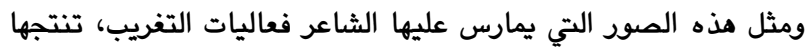
نصوصه الشعرية من رؤية خاصة، تعمل على تغريب النص الشعري في

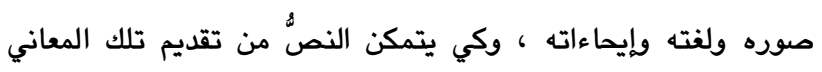

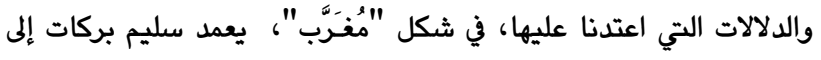
الجمع بين المتناقضات من الصور والمعاني، فيمنح نصه الشعري دلالة مختلفة في التشكيل والتصود والرؤيا.

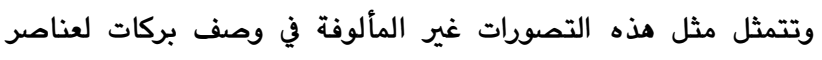

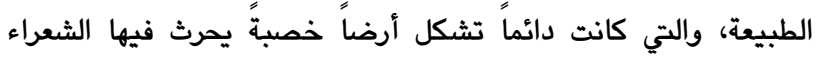
لغتهم، ويحصدون منها قصائدهم، يقول:

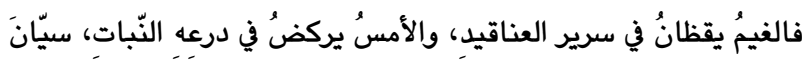
أن يسرق النبيذُ من يديه الكؤوسن، أو ينْقضَ الهواءُ مواثيقهُ الأخيرة. يا برقُ، يا مغْزَلاً دار بين يديْن لا ترفعانِ إلاّ العويلَ، رفّق رغيفَكَ، رَفِقْ
تصورات واستعارات مجسدة للوقت مثل:

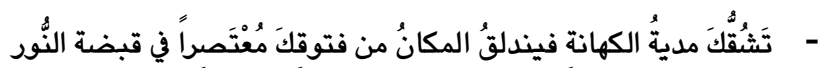

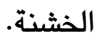
- - مانظر الفجرَ الذئبةَ" الفجرَ بأثدائه الستة.

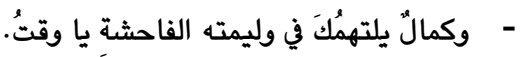

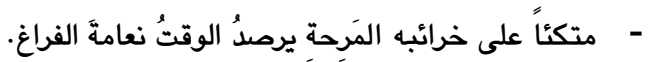

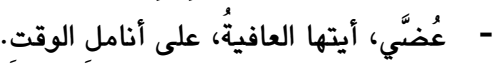

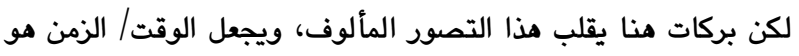

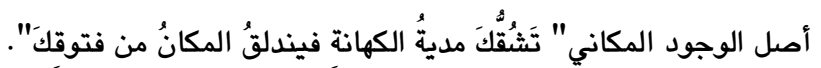

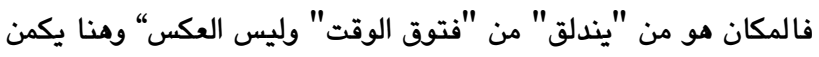
جانب التغريب في الصورة. ويالتالي يكون التغريب في الاستعارة ، كما يكون التغريب في العلاقة بين طرفي التشبيه من الناحية الفنية واللغوية.

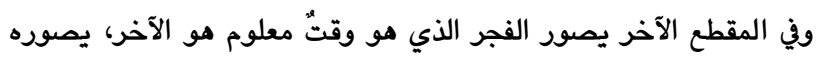

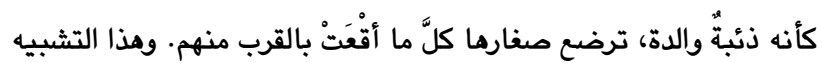

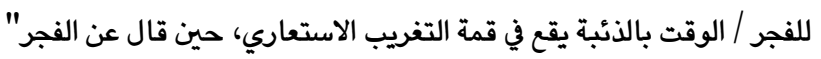

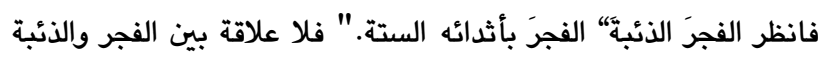
سوى خروج الذئبة في وقت الفجر للصيد. ومثل هذا التشبيه يكون سبباً في إحداث التغريب أو إحداث ((تلك الحالة

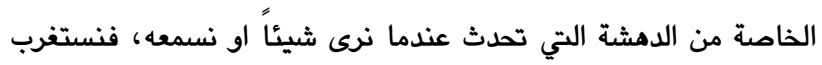

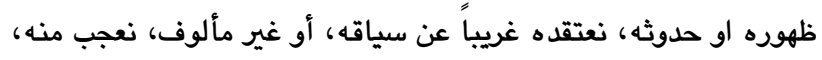

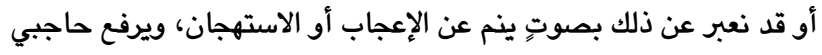

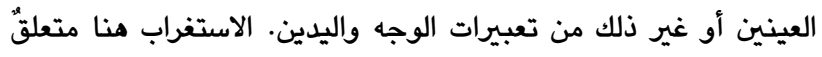

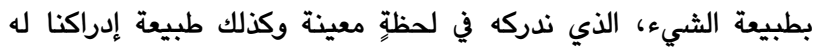

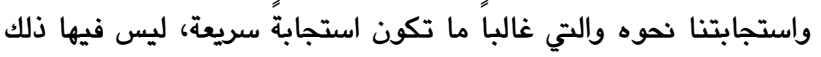
العمق الوجداني او الانفعالي أو ذلك البعد المعرفي المرتبط بظاهرة البكاه 25 (الغرابة.)

فالتغريب الناشئ من الاستعارات، والتشبيه غير المألوف، يتخذ اللغة

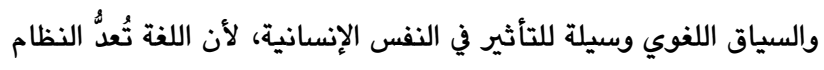
الاقوى تأثيراً في تكوين الذائقة الإنسانية الفردية والجماعية.

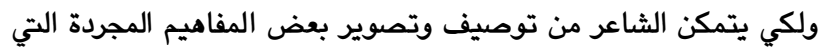

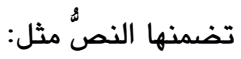

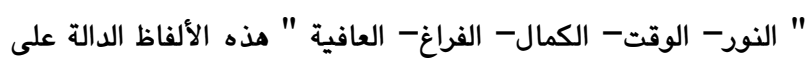

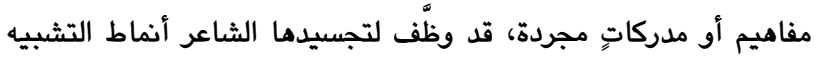

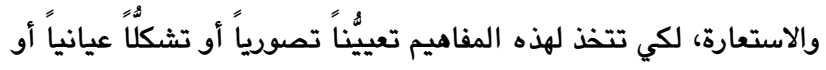

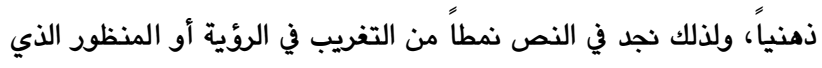




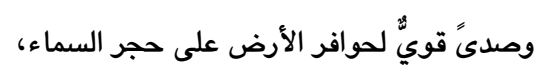

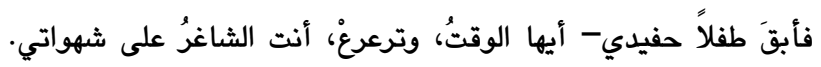

وأصعدْ معي درجات القبر إلى أُبوتُتي حيث الأبديةُ مغدورة تتماثل

[لشفاء...]

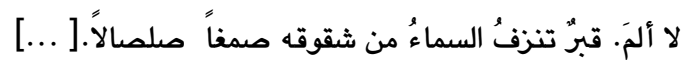

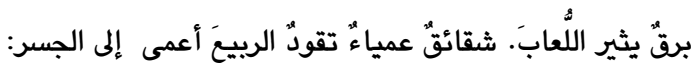
" كنت أباً أيتها الحقيقة.

بعلُكِ النهايةُ يستجير بالأنثِِّي كي يحمي الذَّكَرَ الذي كنته، 29

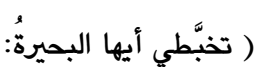

البَجَع يذبحُ الأفقَ بأجنحته على مائدة الشمس). 30

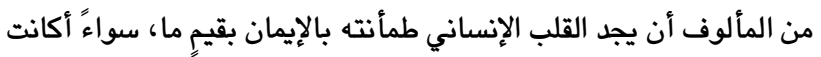

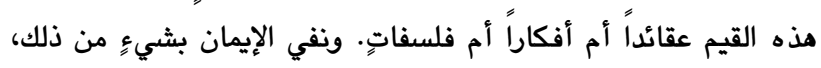

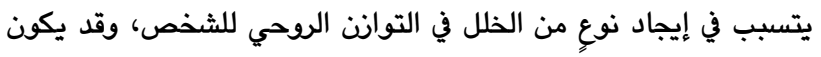
هذا الخلل شكلاً من أشكال الخوف أو القلق أو الغرابة، التي وصفها

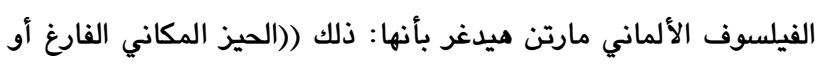

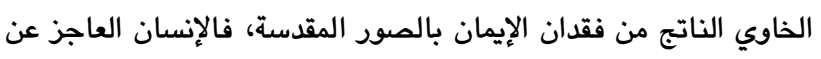
الإيمان يُترك غريباً في الفراغ والعدم.)) والإيمان هو ما يستولي على القلب عادةً، ويجيره من أسباب قلقه

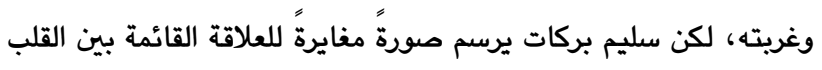

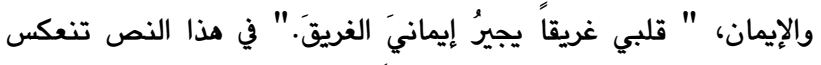

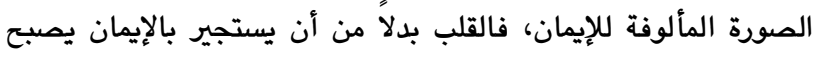

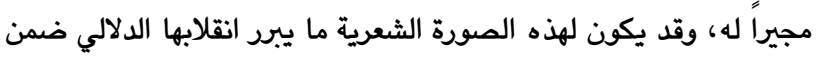

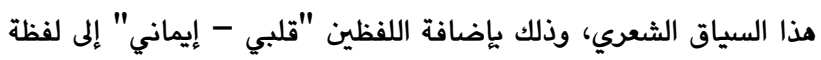

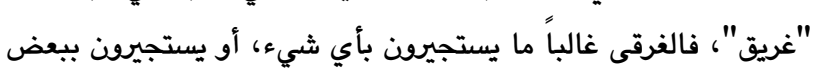

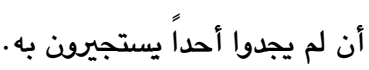

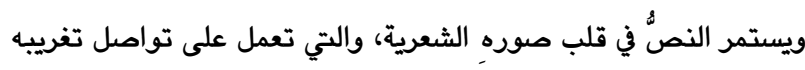

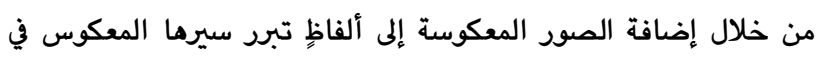

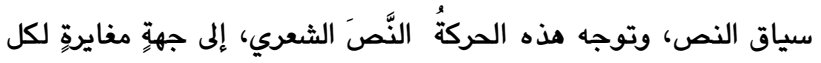

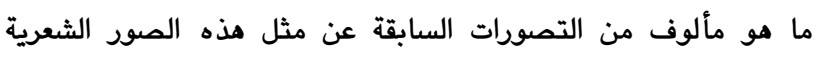

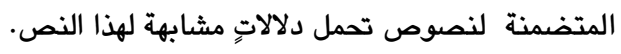

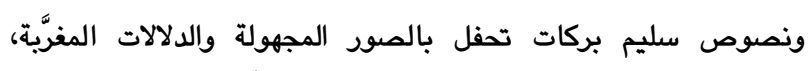
باستخدام تقنية عكس الدلالة أو قلب الصور رأساً على عقب، يقول عن بال

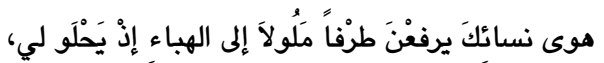

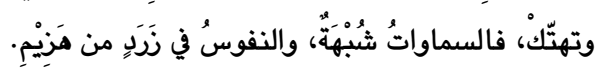
إصعدي يا طرائدَ اليأسِ حتى جحيمي .

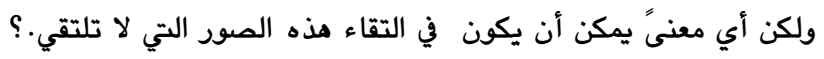

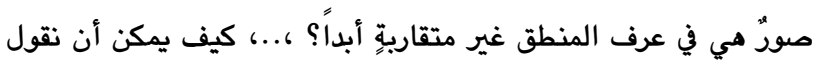

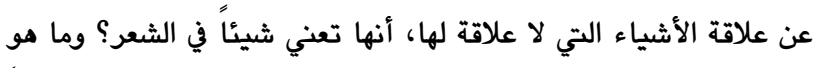

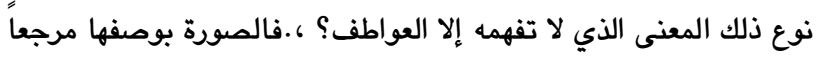

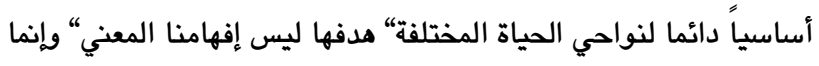
هدفها خلق معني له طريقته الخاصة في إدراك الموضوع. 27 إن الصورة المغرَّة أو المعكوسة تساعد على إضفاء دؤيةٍ جديدة وتحديد

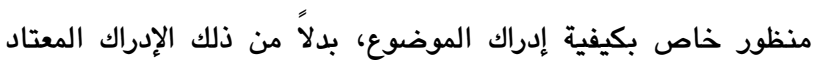
للمعنى. والصورة الشعرية التي يغلب عليها التغريب، هي التي تمنح النص مقاريته

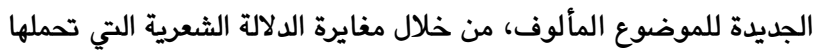

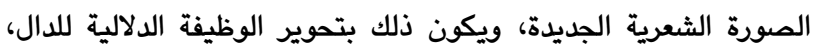

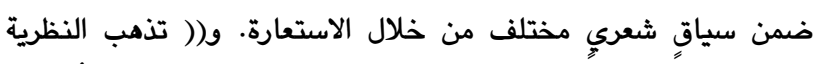

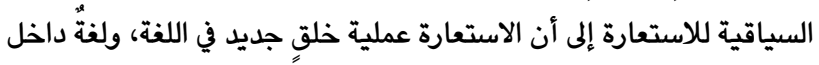

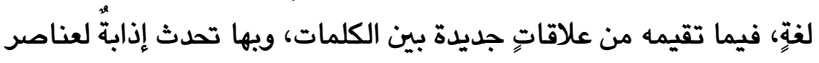

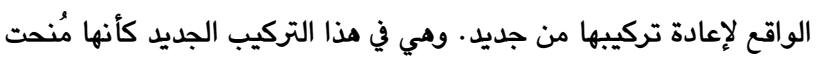

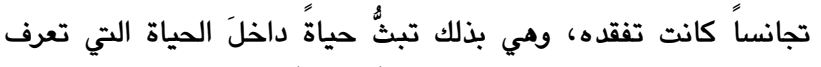

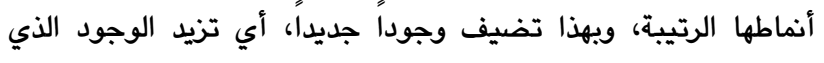
نعرفه، هذا الوجود الذي تخلقه علاقات الكلمات بواسطة تشكيلاتٍ لغوية النية عن طريق تمثيلٍ جديد.() إن تقنية التغريب تكمن في تحوير الوظيفة الدلالية للصور الشعرية، وجعلها

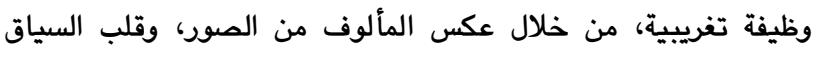

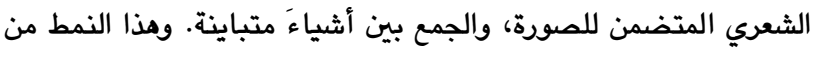

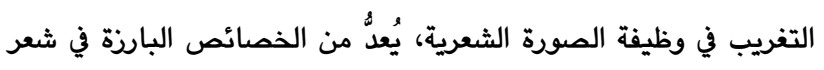

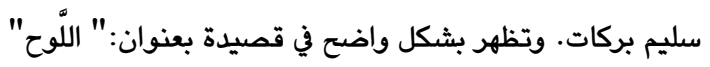

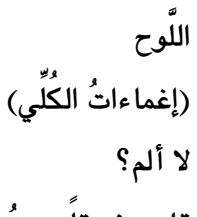
قلبي غريقاً يجيرُ إيمانيَ الغريقَ. رئتايَ تجيران الهواءَ ممزَّتتينِ في هبوبِ أنقاضيَّ عليَّ.

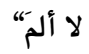
خدعةٌ عذبة كلُّ هذا، 
الساحر لا يمكن ذبحه فداءً لقدسية التاريخ المرتجل زمنياً، والهوية

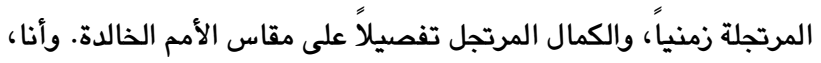

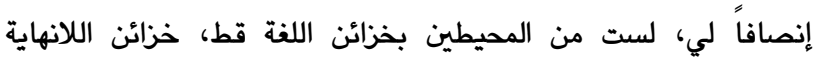

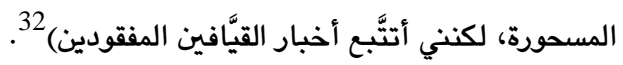

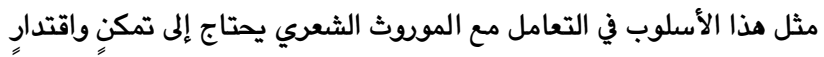

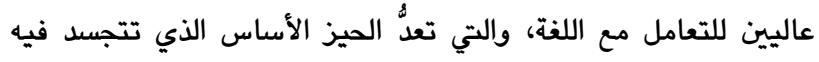

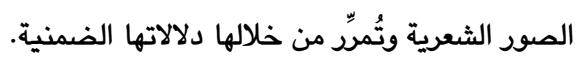

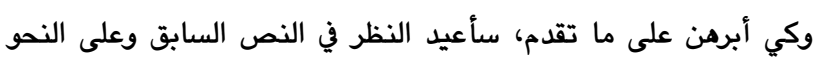
التالي : وحي إنرين الصور العادية المفترض الصور المعكوسة "المغرَّبة" فضاء التغريب

\begin{tabular}{|c|c|c|}
\hline الغريق يجير & قلبي غريقاً يجير إيماني & إيماني يجير قلبي الغريق \\
\hline ممزقتين تجيران & رئتايَ تجيران الهواء & الهواء يُجير رئتايَ \\
\hline 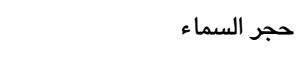 & صدى" قوي” لحوافر الأرض على حجر السماء & صدى حوافر السماء على حجر الأرض \\
\hline الوقت طفلاً ترعرع & فابق طفلاً حفيدي- أيها الوقتُ، وترعرع & طفلاً أترعرع فيك أيها الوقت \\
\hline وأصعدْ درجات القبر & وأصعدْ معي درجات القبر إلى الأبُّوة & لا تنزل معي درجات القبر \\
\hline ت تنزف صلصالاً & قبرّ تنزفُ السماءُ من شقوقه & قبرّ" تنزف الأرض من شقوقه \\
\hline 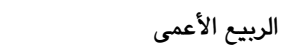 & شقائقٌ عمياءٌ تقودُ الربيع & الربيع يبعث شقائقه المتفتحة \\
\hline يستجير بالأنثوّي ليحمي الذكر & بعلكِ النهايةُ يستجير بالأنثوِيِ & الأنثى تستجير بالذكر لتحمي نفسها \\
\hline يذبح على مائدة الشمس & البَجَعُ يذبحُ الأفقَ بأجنحته & أجنحة البجع تملأ الأفق بالحياة \\
\hline
\end{tabular}

وهنا يظهر التغريب في الدلالة من خلال البنية التركيبية للنص، بجعل

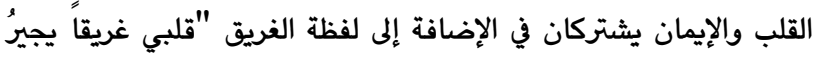

$$
\text { إيمانيَ الغريقَ" والإيمان يشتر }
$$

ويستمر النص الشعري بتغريب دلالاته من خلال عكس الصور الشعرية عن طريق إضافة بعض الألفاظ المدددة إلى بنية النص التركيبية المكونة

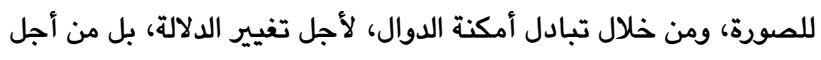
تغريبها، فشاعرٌ مثل سليم بركات (لا يحفل بالمنطق الدلالي السَّائد بين

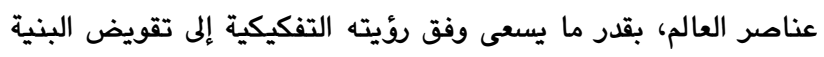

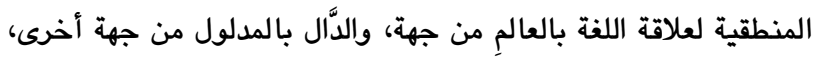

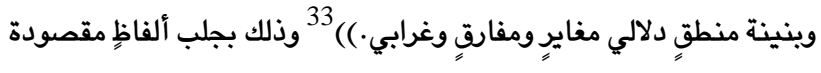

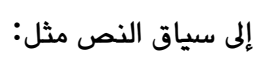

( محاكاة المجهول هي التي قادتني إلى أن أتتَّبع ما تبيحه اللغة لنفسها

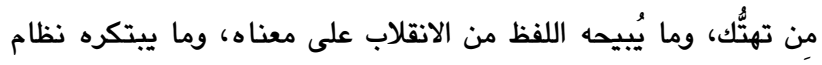
المعنى، في انحلاله سديماً إلى سديم، من الخيانة الطاهرة.

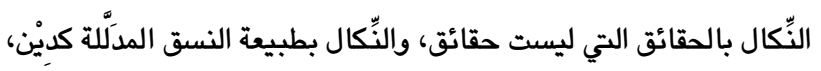

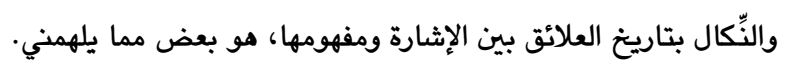

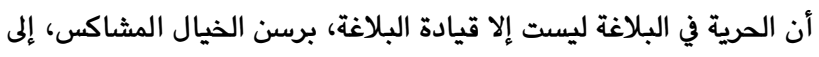

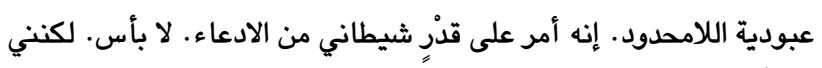

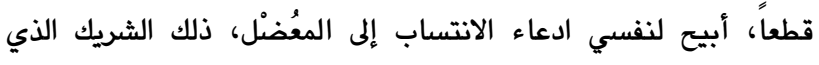

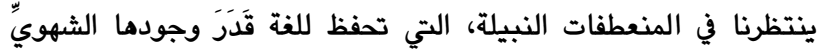

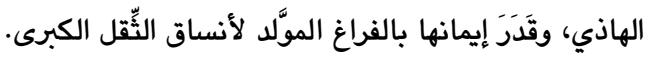

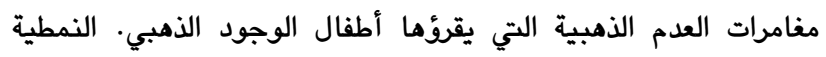

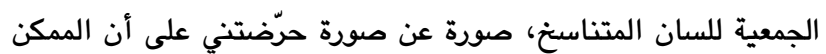
يبدأ النصٌُ باستفهام خرج لمعنى التعجب "لا ألم؟" استفهامٌ عن حال

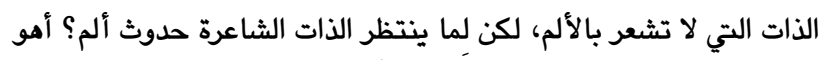

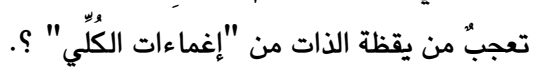

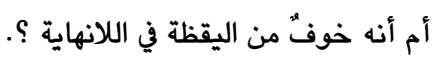

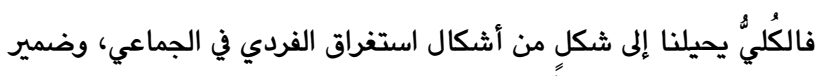

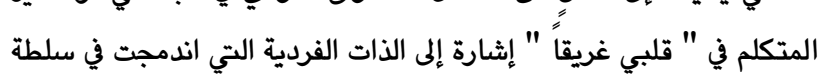

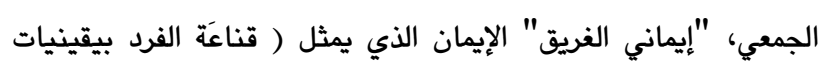

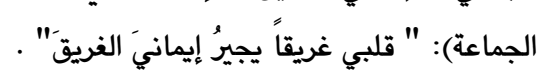

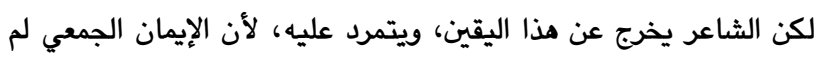

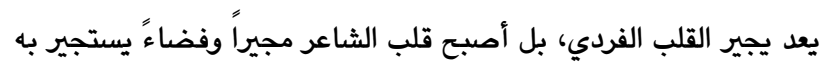

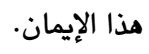


(10) شاعرية أحلام اليقظة "علم شاعرية التأملات الشاردة ": غاستون باشلار،

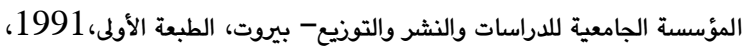

ص15.

(11) الأعمال الشعرية " الشباك ذاتها بالثعالب التي تقود الريع"، قصيدة

$$
\begin{aligned}
& \text { "العنكبوت"، ص ص295- } 296 . \\
& \text { (12) شاعرية أحلام اليقظة، ص158. } \\
& \text { (13) المصدر نفسه، ص99. }
\end{aligned}
$$

(14) اللغة الفنية: مجموعة مؤلفين ، ص54.

(15) موسوعة كامبريدج للنقد الأدبي الكلاسيكي ، الجزء التاسع "القرن العشرين،

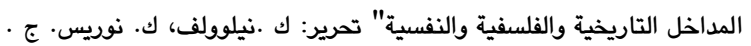

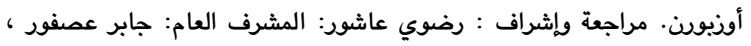

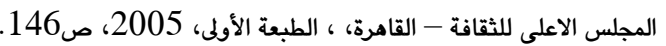
(16) التعجيل في قروض النثر: سليم بركات، دار الزمان للطباعة والنشر والتوزيع-

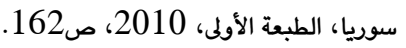

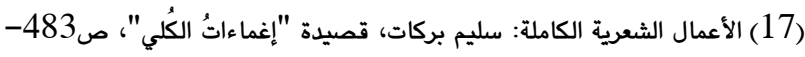
.484

(18) الصورة الشعرية: سي دي لويس، ص74.

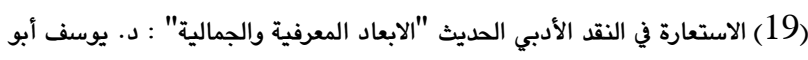

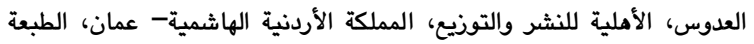

$$
\text { (20) العربية الأولى، 1997، ص220. }
$$

(21) الاستعارة في النقد الأدبي الحديث: يوسف أبو العدوس، ص231. (22) الخيال الأدبي :نور ثروب فراي، ترجمة: حنا عبود، منشورات وزارة الثقافة في

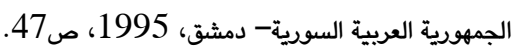

(23) التعجيل في قروض النثر: سليم بركات، 114.

(24) جماليات المكان: جماعة من الباحثين، منشورات عيون المقالات، باندوغ - الدار

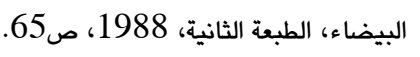

(25) الفن والغرابة: د. شاكر عبد الحميد " مقدمة في تجليات الغريب في الفن والحياة

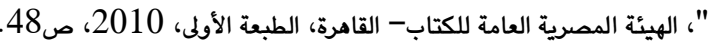

(26) الأعمال الشعرية الكاملة، من مجموعة " بالشَّباك ذاتها بالثعالب التي تقود

$$
\text { الريع"، قصيدة " قلقّ في الذهب "، ص 341- } 349 .
$$

(27) ينظر سيمياء الكون: يوري لوتمان، ترجمة: عبد المجيد نوسي، المركز الثقافي

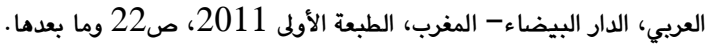

(28) الاستعارة في النقد الأدبي الحديث: د. يوسف أبو العدوس، ص99.

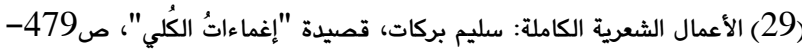

.480

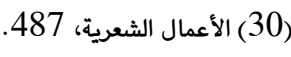

"غريق، تجيران، حجر، طفلاً، ترعرع، عمياء، أعمى، كنت أباً، يذبح،

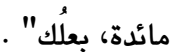
هذه الدوال المقصودة هي التي تعمل على توجيه الدلالة التي تنطوي عليها الصور الشعرية، وهذا التوجيه المغاير للدلالة الناتج من وضع ألفاظٍ بعينها ضمن علاقٍٍ محددة مع ألفاظ أخرى محددة، مو ما يمنح للصور الشعرية تغريبها مثل: - الشئ (قلبي يجير إيماني - رئتاي تجيران الهواء- أبق طفلاً أيها الوقت- حوافر الأرض على حجر السماء- قبرّ تنزف السماءٌ من شقوقه - بعلك يستجير

$$
\text { بالأنثوي- البجع يذبح الأفق). }
$$

كلٌّ هذه الصور الشعرية في نصِّ بركات قد تمرَّت على المألوف منها ضمن مثل هذه السياقات النصية، والتي يمكن أن تكون صوراً شعرية أخرجت إخراجاً مغرَّاً، في قصدية فنية تحاول ان تقول شيئاً عن فلسفة الذات الشاعرة لكن بشكل مختلف غير مألوف، فكانت تقنية الصور الشعرية بما تمتلك من قدرات مهارية في تقريب المفاهيم والإدراكات العقلية وجعلها في صور، هذه التقنية الشعرية كانت من التقنيات المهمة في السيطرة على التصورات الشعرية وإخراج هذه التصورات بما يتناسب مع

$$
\text { الإمكانيات اللغوية للشاعر · }
$$

\section{5. الهوامش}

(1) الصورة الشعرية : سي دي لويس، ترجمة : أحمد نصيف الجنابي، مالك ميري،

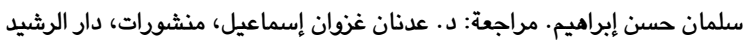

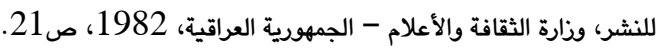
(2) (2) المصدر نفسه ، ص32. (3) قراءة الصورة وصور القراءة : د. صلاح فضل، منشورات دار الشروق - القاهرة،

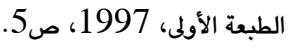
(4) اللغة الفنية : مجموعة من المؤلفين، تعريب وتقديم: د. محمد حسن عبد الله، دار

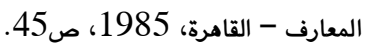
(5) في نظرية العنوان "مغامرةٌ تأويلية في شؤون العتبة النصية ": د. خالد حسين

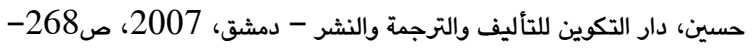

.269

(6) الأعمال الشعرية: سليم بركات، المؤسسة العربية للدراسات والنشر- بيروت،

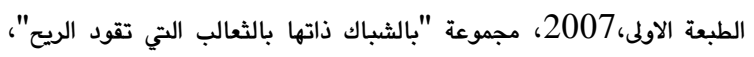

$$
\text { قصيدة "العنكبوت"، ص295- } 296 \text { ـ } 296 \text {. }
$$

(7) : سورة العنكبوت : الآية 41. (8) الأعمال الشعرية "بالشباك ذاتها بالثعالب التي تقود الريح"، قصيدة "العنكبوت"، ص295-296. (9) في نظرية العنوان: د. خالد حسين حسين، ص278. 
شاعرية أحلام اليقظة "علم شاعرية التأملات الشاردة ": غاستون باشلار، المؤسسة

الجامعية للدراسات والنشر والتوزيع- بيروت، الطبعة الأولى، 1991.

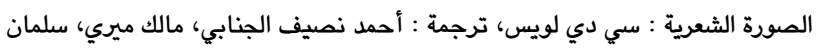

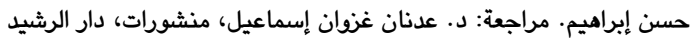

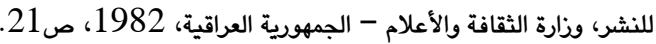

الفن والغرابة: د. شاكر عبد الحميد " مقدمة في تجليات الغريب في الفن والحياة "، الهيئة المصرية العامة للكتاب- القاهرة، الطبعة الأولى، 2010.

في نظرية العنوان "مغامرةٌ تأويلية في شؤون العتبة النصية ": د. خالد حسين حسين،

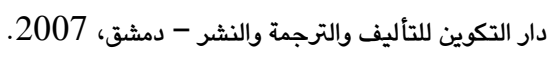

قراءة الصورة وصور القراءة : د. صلاح فضل، منشورات دار الشروق - القاهرة، الطبعة الأولى، 1997، ص5 5 .

اللغة الفنية : مجموعة من المؤلفين، تعريب وتقديم: د. محمد حسن عبد الله، دار المعارف

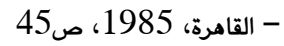

موسوعة كامبريدج للنقد الأدبي الكلاسيكي ، الجزء التاسع "القرن العشرين، المداخل التاريخية والفلسفية والنفسية" تحرير: ك .نيلوولف، ك . نوريس. ج · ل أوزيورن. مراجعة وإثراف : رضوي عاشور: المشرف العام : جابر عصفور ، المجلس الاعلى للثقافة - القاهرة، ، الطبعة الأولى، 2005.

نظرية المنهج الشكلي " نصوص الشكلانيين الروس" : تودوروف، ترجمة: إبراهيم

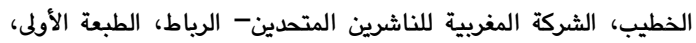

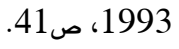

الغرابة "المفهوم وتجلياته في الأدب": د. شاكر عبد الحميد، منشور ضمن سلسلة عالم المعرفة - الكويت ،عدد 384 ، يناير 2012.
(31) ينظر الغرابة "المفهوم وتجلياته في الأدب": د. شاكر عبد الحميد، منشور ضمن

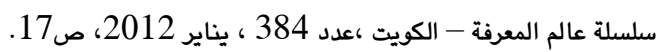

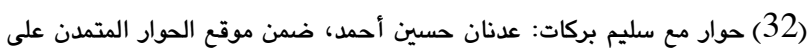
بتاريخ 1-11-12004ttp://www.ahewar.org

(33) في نظرية العنوان: د. خالد حسين جسين، ص281.

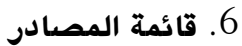

الاستعارة في النقد الأدبي الحديث "الابعاد المعرفية والجمالية" : د. يوسف أبو العدوس، الأل

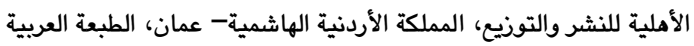

الأولى، 1997.

الأعمال الشعرية: سليم بركات، المؤسسة العربية للدراسات والنشر- بيرت، الطبعة

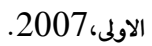

التعجيل في قروض النثر: سليم بركات، دار الزمان للطباعة والنشر والتوزيع- سوريا، الطبعة الأولى، 2010.

جماليات المكان: جماعة من الباحثين، منشورات عيون المقالات، باندوغ - الدار البيضاء، الطبعة الثانية، 1988.

حوار مع سليم بركات: عدنان حسين أحمد، ضمن موقع الحوار المتمدن على بتاريخ 1-11http://www.ahewar.org

الذيال الأدبي :نور ثروب فراي، ترجمة: حنا عبود، منشورات وذارة الثقافة في الجمهورية العربية السورية- دمشق، 1995.

سيمياء الكون: يوري لوتمان، ترجمة: عبد المجيد نوسي، المركز الثقافي العربي، الدار البيضاء- المغرب، الطبعة الأولى 2011. 


\title{
Alienation of the Poetic Image of Salim Barakat
}

\begin{abstract}
:
Alienation means breaking familiarity on the level of significance and meaning; however, understanding the meaning of alienation in literary work needs more efforts and explanations. It is a new concept of an old theme and a modernization of worn repetition status. The function of alienation in the literary work creates shocking and astonishing the audience, confusing their conviction and loosening their postulates, leading them to consider their intellectual backgrounds and real convictions. Here, there is always confusion between the terms 'alienation, mysteriousness, strangeness, peculiarity and abnormality'. Mysteriousness is thus different from alienation in the fact that the former is connected with fear of seeing or hearing unfamiliar things, showing aesthetic experiences as unpleasant and terrifying. Mysteriousness may provoke in us a sense of fear, laughter or astonishment. There is also a difference between the terms 'strangeness' and 'alienation'. Strangeness is mixing between familiar and unfamiliar things. It may take a special form of a familiar thing, which is not expected by a strange person. This thing may be beautiful but scary in the same time. Further, alienation differs from peculiarity in fact that the latter is everything that is not immediately recognized by human perception. It is a temporary interruption of personal background. Abnormality means hesitation in perceptual judgment on the side of beings when facing an abnormal event. Alienation in poetic texts aims at transferring the perceived and usual things to specific amazing ones to surprisingly make intuitive things more mysterious, attractive and perceptual. Alienation in Salim Barakat's poems results from using expressive linguistic techniques such as simile and metaphor. All of them break familiarity through expressive methods and expressions, achieving technical literary values for everything usual and familiar in linguistic poetic texts in terms of form and meaning. That is why, one is astonished when reading his poems when words create their special context and find their meanings. This is all fulfilled through words, signs, codes and contexts of the poetic language. Hence, the meaning of this language leads to thinking and alienation, which is a technique intending to affect interpretative capabilities and break the horizons of contexts continuously.
\end{abstract}

Keywords: Alienation, Poetic, Image, Salim Barakat. 